\title{
Failing Communication with Inmates: An Explorative Study of the Content of the Letters from the Correctional Services
}

\author{
Erik Søndenaa ${ }^{1,2 *}$, Marit Wangsholm³, Valentina C. Iversen ${ }^{4,5}$ \\ ${ }^{1}$ Forensic Department Brøset, St. Olav's Hospital, Trondheim, Norway \\ ${ }^{2}$ Regional Centre for Child and Youth Mental Health and Child Welfare, Regional Habilitation Unit, Faculty of \\ Medicine, Norwegian University of Science and Technology (NTNU), Trondheim, Norway \\ ${ }^{3}$ Correctional Services, Region North, Trondheim, Norway \\ ${ }^{4} \emptyset$ stmarka Department, St. Olav's University Hospital, Trondheim, Norway \\ ${ }^{5}$ Department of Neuroscience, Faculty of Medicine, Norwegian University of Science and Technology (NTNU), \\ Trondheim, Norway \\ Email: ${ }^{*}$ erik.sondenaa@ntnu.no
}

Received 11 February 2015; accepted 13 March 2015; published 16 March 2015

Copyright (c) 2015 by authors and Scientific Research Publishing Inc.

This work is licensed under the Creative Commons Attribution International License (CC BY). http://creativecommons.org/licenses/by/4.0/

(c) (i) Open Access

\begin{abstract}
An important part of the communication between the correctional authorities and convicted persons presupposes the ability to read and write. Reading skills among prisoners have been stated as a significant problem in a large number of studies. The written language in the Norwegian public sector has been reviewed in the last five years to improve language and decrease costs based on misunderstandings. The aim was to explore the prevalence and nature of reading problems associated to letters from the correctional service to the inmates. A cross-sectional study using a semi-structured questionnaire $(n=190)$ where all participants were convicted persons was used. The selection was consecutive over a period of six months. The response rate was $95 \%$. Most inmates understood the letters $\mathbf{( 7 8 \% )}$ ), but the rate of difficult words in the letter was described by $63 \%$. The difficulties were correlated to the different security levels, giving more difficulties in the most restrictive placements. Letters responding to the participants' applications were rated as more difficult. A significant proportion of the Norwegian convicted persons reported problems in understanding parts of the letters sent to them. The consequences were in some cases humiliating and might have potential of breaching the personal legal protection.
\end{abstract}

\section{Keywords}

Reading Comprehension, Correctional Services, Plain Language, Mental Health

\footnotetext{
*Corresponding author.
}

How to cite this paper: Søndenaa, E., Wangsholm, M. and Iversen, V.C. (2015) Failing Communication with Inmates: An Explorative Study of the Content of the Letters from the Correctional Services. Open Journal of Social Sciences, 3, 144-149 http://dx.doi.org/10.4236/iss.2015.33023 


\section{Introduction}

The research regarding reading problems among delinquents has been extensive during the last few decades [1] [2]. Estimates of reading difficulties among prison inmates in the Scandinavian countries vary from $30 \%$ to $70 \%$ in the prison population [3]-[6] compared to $5 \%$ to $8 \%$ in the community samples [7]. This significantly higher incidence has been reported in numerous studies [4] [8]-[10]. The figure seems to be reliable across countries and cultures and a causal relationship between school failure and later delinquent behaviour has been suggested [8]-[10]. Svensson (2010) argued that reading problems should be concerned separately from dyslexia, and that the relationship between reading problems and conduct disorders had more impacts. The causality would then give two separate procedures. If the reading problems constituted the primary disorder, the focus should be on pedagogical treatment. This hypothesis is supported in several studies [10]-[12]. If the conduct problems were primary, a psychiatric treatment might be preferable as suggested in other studies [13] [14].

According to the Diagnostic and Statistical Manual of Mental Disorders (DSM-IV) [15], the concept of reading disorders is described as "A. Reading achievement, as measured by individually administrated standardized tests of reading accuracy or comprehension, is substantially below that expected given the person's chronologi$\mathrm{cal}$ age, measured intelligence, and age-appropriate education. B. The disturbance in Criterion A significantly interferes with academic achievement or activities of daily living that require reading skills. C. If a sensory deficit is present, the reading difficulties are in excess of those usually associated with it" (code 315.00, DSM-IV).

The consequences of having reading problems as an inmate in the correctional services have been studied sparsely, although some articles have argued for language improvements because of the ambiguous phrases and abstruse terms in parts of the judicial language [16] [17]. The criticism of the law language has been seized on by flourishing consumer movements during the last decades and produced the Plain Language Movement (PLM) [18]. The fundamental idea promoted by the PLM is that since the law is addressed primarily to ordinary citizens, rather than lawyers and judges, it should be drafted so as to be fully intelligible to those affected by it. This may be achieved by drafting the law in plain language, and stripping it of its dense, technical and convoluted style [19]. Most English speaking and several other countries have adopted plain language policies and prepared manuals for drafting legislation and governmental forms in plain language. The conviction that plain language makes the law significant intelligible to laypeople has in the last years addressed criticism maintaining that several complex aspects of the law are not eliminated by mere simplification of the language. Assy (2011) described a weak empirical basis including methodological and statistical fallacies, and argued that the details of the law require a minimum of verbal complexity. The criticism has been met with statistical proofs and arguments that "terms of art are rarer and more replaceable than lawyers like to think" [20].

The plain language in Norway's civil services was initiated in 2008. From the beginning, more than 60 governmental agencies received funding to implement measures that made communication with the users simpler and more users friendly. The project concluded in 2012 that an overall Plain Language integration of the agencies' overall management system was needed to obtain the goals for the continued Plain Language efforts [21]. A study on the professional language in the judicial sector found that the case handlers themselves were confident with their mode of written expression and that they cared for the public reader. However they criticized the rule of law as being too difficult in linguistics [22].

Studies conducted among prison inmates are conclusive in pointing out reading difficulties as a vulnerability correlated to delinquent behaviour, and the ongoing aim at improving and simplifying the language has a priority in the politics. Although the reading capacity is limited in a large number of inmates, studies on the inmates' understanding of essential information associated to their sentence have not been recently studied. The current study seeks to identify how prison inmates evaluate the readability of letters received from the prison authorities. What differences are found between those inmates who understand the words and the content of the letter and those who don't understand? Whereas the majority of studies on the perception of reading competency have been conducted on general reading skills, this study is limited to the letters relevant to the inmates' sentence.

\section{Methods}

\subsection{Participant}

The subjects were 190 inmates serving sentences in different levels of prison facilities in the Norwegian Correctional Service Region North. Non-Norwegian speaking prisoners were excluded. All other inmates were in- 
cluded. The inclusion criteria were that the person had received a letter from the correctional services during the last week (seven days). During a period of three months in 2013, all inmates receiving letters were asked to participate. The correctional units included in the study consisted of a high secure prison with 144 beds, a medium secure prison with 60 beds, and two units for probation sentences. The gender distribution was 170 men and 20 women and the mean age was 34.7 (range 18 - 72). The age distribution and the male/female ratio corresponded well to the general prison population in Norway [23].

\subsection{Measures}

Information about placement and type of sentence was given. A semi-structured interview was conducted in order to obtain data on gender, age, civil status, preferred language, education, health, employment and offending history correctional. Six questions concerning the content and the readability of the received letter ended the assessment. These questions dealt with the understanding of the overall content, the understanding of the language, the use of difficult words, the adequacy of information and the letters from the correctional services compared to other public letters. Each question was rated on a 5-point scale rated between 0 (No problems) and 4 (Severe problems), reflecting the extent to which a particular problem was present when reading the letter.

\subsection{Procedure}

The participants were informed about the study and signed a written consent. The interviews were executed by the prison officer with a contact responsibility to the participant. The project group had several meetings with the prison officers in the preparation, implementation of the study and during the data analysis. The interviews were conducted within a week after the receipt of the letter and each interview took about 30 minutes.

The research project was approved by the Regional Committé for Medical and Health Research Ethics (reference 2013/389) and the Correctional Services region North (reference 2009/00463-120/602).

\subsection{Data Analysis}

Statistical analysis was performed using the SPSS statistical package 21. Chi-square tests and Mann-Whitney U tests were used for differences between continuous and categorical groups, respectively. The main outcome, “understanding the letters" from Correctional Services (yes/no), was studied using Mann-Whitney's test. The letters were divided and studied in two categories: 1 ) letters with decisions about transference, leave of absence or discharge and 2) letters with notices, instructions and messages. In the analysis age and gender were excluded due to no association with the outcome variable.

The level of significance was set at 0.05 . Comparisons were made between the two groups.

\section{Results}

The educational distribution of the sample showed that 189 (99.5\%) had completed primary school, 156 (82.1\%) had entered high school, 96 (50.5\%) had completed high school, and 33 (17.4\%) had some college or university education. Reading and writing difficulties were described as problematic by 40 (21.1\%) of the inmates. Difficulties in understanding letters from Correctional Services was appointed by $42(22 \%)$ of the inmates. An education history with special education in childhood was confirmed by 68 (35.8\%) of the inmates. Fifty three (28\%) of the inmates considered having current mental health problems and 29 (15.4\%) reported having mental health problems in childhood. Table 1 shows the comparison of mental health of inmates in childhood and in the adulthood and their difficulties in understanding letters from correctional services, understanding language in the letters from correctional services, understanding the words in the letters from correctional services, reading and writing difficulties, having difficulty concentrating, and of level of education.

As the data was skewed (not normally distributed) the most appropriate statistical test was non-parametric tests. Most of the respondents $(\mathrm{N}=119,62.6 \%)$ had been previously convicted for a crime and amongst these persons the median were 2, ranging from 1 to 35 previous convictions. Participants with difficulties in understanding letters (Median $=3$ ) didn’t seem to differ in the number of previous convictions compared to the participants without such difficulties (Median $=2$ ), $\mathrm{U}=845.5$.

The letters were divided into two groups: 1) letters with decisions about transference, leave of absence or discharge and 2) letters with notices, instructions or messages. Letters categorized in group 1 counted 77 letters 
Table 1. Type of difficulties present and mental health problems experienced in childhood and adulthood by inmates.

\begin{tabular}{|c|c|c|c|c|c|c|}
\hline \multirow[t]{2}{*}{ Type of difficulties } & \multicolumn{2}{|c|}{$\begin{array}{l}\text { Mental problems } \\
\text { in childhood }\end{array}$} & \multirow[t]{2}{*}{$\begin{array}{c}\text { Comparisons } \\
\text { between groups }\end{array}$} & \multicolumn{2}{|c|}{$\begin{array}{l}\text { Mental problems } \\
\text { in adulthood }\end{array}$} & \multirow[t]{2}{*}{$\begin{array}{c}\text { Comparisons } \\
\text { between groups }\end{array}$} \\
\hline & $\begin{array}{c}\text { No } \\
(n=159)\end{array}$ & $\begin{array}{c}\text { Yes } \\
(n=29)\end{array}$ & & $\begin{array}{c}\text { No } \\
(n=136)\end{array}$ & $\begin{array}{c}\text { Yes } \\
(n=53)\end{array}$ & \\
\hline $\begin{array}{l}\text { Understanding letters from } \\
\text { correctional services }(N=42)\end{array}$ & $30(19 \%)$ & $12(41 \%)$ & $\begin{array}{l}\chi^{2}=7.70 \\
(\mathrm{df}=1) \mathrm{p}=0.01\end{array}$ & $29(21 \%)$ & $13(25 \%)$ & $\begin{array}{l}\chi^{2}=0.02 \\
(\mathrm{df}=1) \mathrm{p}=0.546\end{array}$ \\
\hline $\begin{array}{l}\text { Understanding language in the letters } \\
\text { from correctional services }(\mathrm{N}=57)\end{array}$ & $42(26 \%)$ & $15(52 \%)$ & $\begin{array}{l}\chi^{2}=7.89 \\
(\mathrm{df}=1) \mathrm{p}=0.005\end{array}$ & $42(31 \%)$ & $15(28 \%)$ & $\begin{array}{l}\chi^{2}=0.37 \\
(\mathrm{df}=1) \mathrm{p}=0.338\end{array}$ \\
\hline $\begin{array}{l}\text { Understanding the words in the letters } \\
\text { from correctional services }(\mathrm{N}=119)\end{array}$ & $102(64 \%)$ & $17(59 \%)$ & $\begin{array}{l}\chi^{2}=0.85 \\
(\mathrm{df}=1) \mathrm{p}=0.358\end{array}$ & $84(60 \%)$ & $35(66 \%)$ & $\begin{array}{l}\chi^{2}=0.30 \\
(\mathrm{df}=1) \mathrm{p}=0.585\end{array}$ \\
\hline Reading and writing difficulties $(\mathrm{N}=39)$ & $24(15 \%)$ & $15(52 \%)$ & $\begin{array}{l}\chi^{2}=20.01 \\
(\mathrm{df}=1) \mathrm{p}=0.000\end{array}$ & $28(21 \%)$ & $11(21 \%)$ & $\begin{array}{l}\chi^{2}=0.50 \\
(\mathrm{df}=1) \mathrm{p}=0.480\end{array}$ \\
\hline Having difficulty concentrating $(\mathrm{N}=73)$ & $51(32 \%)$ & $22(76 \%)$ & $\begin{array}{l}\chi^{2}=19.8 \\
(\mathrm{df}=1) \mathrm{p}=0.000\end{array}$ & $42(31 \%)$ & $31(58 \%)$ & $\begin{array}{l}\chi^{2}=11.56 \\
(\mathrm{df}=1) \mathrm{p}=0.001\end{array}$ \\
\hline Level of education & & & $\begin{array}{l}\chi^{2}=4.85 \\
(\mathrm{df}=1) \mathrm{p}=0.028\end{array}$ & & & $\begin{array}{l}\chi^{2}=0.98 \\
(\mathrm{df}=1) \mathrm{p}=0.320\end{array}$ \\
\hline Unfinished secondary $(\mathrm{N}=91)$ & $72(45 \%)$ & 19(66\%) & & $64(47 \%)$ & $27(51 \%)$ & \\
\hline Finished at secondary or more $(\mathrm{N}=96)$ & $87(55 \%)$ & $9(34 \%)$ & & 71(52\%) & $25(48 \%)$ & \\
\hline
\end{tabular}

and in group 2 there was 87 letters. The verbal content of letters in the first group was reported as more difficult compared to the content of second group $\left(\chi^{2}=24.08, \mathrm{df}=1, \mathrm{p}<0.000\right)$.

The understanding of letters was studied with connection to different penal sanctions. The sanctions were divided into highly restricted and low restricted sentences. Letters in the first group were more common to inmates with the high restrictive sentences compared to letters in the second group in where a large number served a community sentence $\left(\chi^{2}=17.24, \mathrm{df}=1, \mathrm{p}<0.000\right)$.

\section{Discussion}

The current study analyzes and explores how prison inmates evaluate the readability and understanding of letters received from the prison authorities. The main finding was that $22 \%$ of the sample described difficulties in understanding the letter and that inmates who described these problems also had difficulties in understanding the language, the words and the text used in the letters. This finding suggests that inmates' difficulties in understanding the letters depended on the way that the letters formed, with bureaucratic and formal concepts as previously found in a variety of studies [16] [17] [20].

Communication is also affected by our expectations toward the interlocutor. Situational variables include norms regarding the writing of such letters from the part of correctional services. Norms are socially shared ideas about what constitutes appropriate or inappropriate behavior in any given situation [24].

It was not verified in this study that separating reading problems are more correlated to conduct problems than to dyslexia as suggested by Svensson (2011), although the impact of reading problems was confirmed by $22 \%$ of the sample. Inmates that described a history of mental health problems in childhood presented more difficulties in understanding the letters, and the combination of previous mental health problems and learning difficulties was present.

The inmates' current mental problems did not significantly correlate to understanding the letters. Childhood mental health and reading/writing problems may have been mutually influenced resulting in a conduct problem, suggesting a combination between pedagogical and medical approaches. However, the concentration problems argued by the inmates may be associated with some kinds of mental disturbance.

For those whose educational level was lower than secondary school, more difficulties in understanding the letters were observed. A suggestion of revisions and simplification in the routines for writing the letters to inmates should be considered to make access to the essential information. The educational level of this study sample is similar to findings in other studies of Norwegian inmates [25] [26] and significant lower than those in the main Norwegian population [27]. Low educated inmates are also found to be more reoffending, less socialadaptive to the criminal services and more vulnerable to mental health problems during incarceration [3] [28]. 
Failure to understand specific words or the nonverbal behaviors of inmates is a part of what has been called "linguistic poverty" [29]. This experience is sometimes followed by aggressive behavior that limits the capacity to communicate [30]. In the current study inmates' difficulty in understanding the words written in the letters was evident. This faulty communication occurred most often in the letters reporting decisions about transference, leave of absence or discharge. One interesting aspect of this finding is that letters to an inmate are more difficult to understand when the content of the letter has an importance for the prison regime compared to letters with notices and call-up papers. Such a practice may cause powerlessness to those who are vulnerable to reading problems. Ineffective communication of information may pervasive in relationships between inmates and correctional services.

\section{Conclusions}

All in all, the current study suggests that communication between inmates and correctional services should be improved. The language used in the letters needs a reform and correctional services must pay attention to the particular and special situation of the inmates. Resources may be available in prison to help those who cannot understand the message sent by correctional authorities. One of the most important aims of the Norwegian correctional services is to rehabilitate the inmate to become a law-abiding citizen, and the fundamental aspect of adaptive communication is then a premise. It is important to separate the inmates' deviant behaviour associated to communication problems and other types of inappropriate behaviour that may be related to the delinquencies. Hence, these findings have implications for the development of interventions aimed to promote better communication between correctional services and the inmates. Probably, the most potent efforts are still on the hand of the prison managers, when adapting their communication into a language that is understood by all inmates. Collaboration between correctional services and targeted user organizations may create new and non-traditional ways of communication, i.e. consultations besides formal correspondence. Improving the written language by directing it into more plain language would be helpful for $22 \%$ of the inmates and probably also for more.

There are limitations to this study due to the solely self-reported information. However the study has documented a democratic problem in the correctional services that may result in inequality based on the reading competency of the inmates. As the written language is the scope of improvements in the correctional services, future studies should focus on the effects and possible side-effects of a plain language.

\section{Acknowledgements}

The authors wish to thank the correctional services, region north for their valuable contribution in participation in the study and collecting data.

\section{References}

[1] Grigorenko, E.L. (2006) Learning Disabilities in Juvenile Offenders. Child and Adolescent Psychiatric Clinics of North America, 15, 353-371. http://dx.doi.org/10.1016/j.chc.2005.11.001

[2] Svensson, I. (2011) Reading and Writing Disabilities among Inmates in Correctional Settings. A Swedish Perspective. Learning and Individual Differences, 21, 19-29. http://dx.doi.org/10.1016/j.lindif.2010.08.002

[3] Manger, T., Eikeland, O.-J., Asbjørnsen, A. and Langelid, T. (2006) Educational Intentions among Prison Inmates. European Journal on Criminal Policy and Research, 12, 35-48. http://dx.doi.org/10.1007/s10610-006-9007-2

[4] Rasmussen, K., Almvik, R. and Levander, S. (2001) Attention Deficit Hyperactivity Disorder, Reading Disability, and Personality Disorders in a Prison Population. Journal of the American Academy of Psychiatry and the Law Online, 29, 186-193.

[5] Samuelsson, S., Herkner, B. and Lundberg, I. (2003) Reading and Writing Difficulties among Prison Inmates: A Matter of Experiential Factors Rather than Dyslexic Problems. Scientific Studies of Reading, 7, 53-73. http://dx.doi.org/10.1207/S1532799XSSR0701_04

[6] Svensson, I. (2009) Att utveckla läs-och skrivförmågan bland elever på särskilda ungdomshem. Ett försök med särskilda insatser [Developing Reading and Writing Skills among Pupils in Special Juvenile Institutions-A Special Effort Attempt]. The National Board of Institutional Care, Stockholm.

[7] Lundberg, I. (1985) Longitudinal Studies of Reading and Reading Difficulties in Sweden. Reading Research. Advances in Theory and Practice, 4, 65-105.

[8] Alm, J. and Andersson, J. (1997) A Study of Literacy in Prisons in Uppsala. Dyslexia, 3, 245-246. 
http://dx.doi.org/10.1002/(SICI)1099-0909(199712)3:4<245::AID-DYS94>3.0.CO;2-2

[9] Kirk, J. and Reid, G. (2001) An Examination of the Relationship between Dyslexia and Offending in Young People and the Implications for the Training System. Dyslexia, 7, 77-84. http://dx.doi.org/10.1002/dys.184

[10] Moody, K., Holzer, C., Roman, M., Paulsen, K., Freeman, D. and Haynes, M. (2000) Prevalence of Dyslexia among Texas Prison Inmates. Texas Medicine, 96, 69-75.

[11] Bennett, K.J., Brown, K.S., Boyle, M., Racine, Y. and Offord, D. (2003) Does Low Reading Achievement at School Entry Cause Conduct Problems? Social Science \& Medicine, 56, 2443-2448. http://dx.doi.org/10.1016/S0277-9536(02)00247-2

[12] Svensson, I., Lundberg, I. and Jacobson, C. (2003) The Nature of Reading Difficulties among Inmates in Juvenile Institutions. Reading and Writing, 16, 667-691. http://dx.doi.org/10.1023/A:1025832815286

[13] Cornwall, A. and Bawden, H.N. (1992) Reading Disabilities and Aggression: A Critical Review. Journal of Learning Disabilities, 25, 281-288. http://dx.doi.org/10.1177/002221949202500503

[14] McMichael, P. (1979) The Hen or the Egg? Which Comes First-Antisocial Emotional Disorders or Reading Disability? British Journal of Educational Psychology, 49, 226-238. http://dx.doi.org/10.1111/j.2044-8279.1979.tb02421.x

[15] American Psychiatric Association (1994) Diagnostic and Statistical Manual of Mental Disorders. Arlington.

[16] Dyer, C.R., Fairbanks, J.E., Greiner, M.L., Barron, K., Skreen, J.L. and Cerrillo-Ramirez, J. (2013) Improving Access to Justice: Plain Language Family Law Court Forms in Washington State. Seattle Journal for Social Justice, 11, Article 10.

[17] Rogers, R., Rogstad, J.E., Steadham, J.A. and Drogin, E.Y. (2011) In Plain English: Avoiding Recognized Problems with Miranda Miscomprehension. Psychology, Public Policy, and Law, 17, 264-285. http://dx.doi.org/10.1037/a0022508

[18] Butt, P. (2013) Modern Legal Drafting: A Guide to Using Clearer Language. Cambridge University Press, Cambridge.

[19] Assy, R. (2011) Can the Law Speak Directly to Its Subjects? The Limitation of Plain Language. Journal of Law and Society, 38, 376-404. http://dx.doi.org/10.1111/j.1467-6478.2011.00549.x

[20] Kimble, J. (2013) You Think the Law Requires Legalese? Michigan Bar Journal, 92, 48-50.

[21] Dahle, M. and Ryssvik, J. (2013) Klart vi kan [Certainly We Can]. Ideas2evidence, Bergen.

[22] Omdal, H. (2013) Kan lovspråk temmes: En undersøkelse om klart språk i lover og forskrifter [Can Legal Terminology tamed: A Survey of Clear Language in Laws and Regulations]. DIFI, Kristiansand.

[23] Ministry of Justice (2006) The Correctional Services Annual Statistics. Oslo.

[24] Wilkinson, R.G. and Pickett, K.E. (2006) Income Inequality and Population Health: A Review and Explanation of the Evidence. Social Science \& Medicine, 62, 1768-1784. http://dx.doi.org/10.1016/j.socscimed.2005.08.036

[25] Friestad, C. (2010) Socio-Economic Status and Health in a Marginalized Group: The Role of Subjective Social Status among Prison Inmates. The European Journal of Public Health, 20, 653-658. http://dx.doi.org/10.1093/eurpub/ckp242

[26] Iversen, V.C., Sam, D.L. and Helvik, A.S. (2013) Psychological Distress and Perceived Health in Inmates in Norwegian Prisons. Scandinavian Journal of Public Health, 42, 171-176.

[27] Friestad, C. and Skog Hansen, I. (2004) Levekår blant innsatte [Living Conditions of Prison Inmates]. FAFO, Oslo.

[28] Søndenaa, E., Rasmussen, K., Palmstierna, T. and Nøttestad, J. (2008) The Prevalence and Nature of Intellectual Disability in Norwegian Prisons. Journal of Intellectual Disability Research, 52, 1129-1137. http://dx.doi.org/10.1111/j.1365-2788.2008.01072.x

[29] Berger, C.R. (2001) Miscommunication and Communication Failure. In: Robinson, P. and Giles, H., Eds., The New Handbook of Language and Social Psychology, Wiley, Chichester, UK, 177-192.

[30] Alberdi, F. and Nørregaard, C. (2002) Transcultural Psychiatry. Narayana Press, Københaven. 